\title{
Research on English Translation of Cross-Border E- Commerce Based on Functional Equivalence Theory
}

\author{
Guangtao $\mathrm{Cao}^{1, *}{ }^{*}$ Jiaqi $\mathrm{Luo}^{2}$
}

\author{
${ }^{1}$ Forieign Languages Department, Guangdong University of Education, Guangzhou, Guangdong 510303, China \\ ${ }^{2}$ School of Foreign Languages, Shaoguan University, Shaoguan, Guangdong 512005, China \\ *Corresponding author. Email:1025420805@qq.com
}

\begin{abstract}
With the development of globalization, it promotes the development of cross-border e-commerce. In the exchange and development of international business, the translation of cross-border e-commerce English plays an irreplaceable role and becomes an important means of international business communication. This paper takes the functional equivalence theory to analyze the characteristics and strategies of cross-border e-commerce English translation and puts forward to the corresponding translation strategies, and further demonstrates that Nida's "equivalence" should not be mechanically applied, but should achieve the most natural equivalence.
\end{abstract}

\section{Keywords: cross-border e-commerce English, functional equivalence theory, translation}

\section{INTRODUCTION}

Recently there are many valuable researches on cross-border e-commerce, for example, Duan (2016) analyzed the characteristics of business English language and translation problems of crossborder e-commerce, [1] Chen and Wu (2018) studied the application of business English in crossborder e-commerce, [2] and Yu and Mei (2014) researched on non-verbal graphic symbol communication of cross-border e-commerce. [3]

As to functional equivalence theory, Zhang (2014) analyzed the lexical translation of business contract under the theory of functional equivalence, [4] He (2019) studied the translation strategy of external publicity from the perspective of functional equivalence theory, [5] and Xue (2014) analyzes Chinese-characterized terms translation on the functional equivalence theory. [6]

In 1964, Eugene A.Nida put forward the famous translation theory of "dynamic equivalence", which is also called "functional equivalence". What "functional equivalence" emphasizes is that translation should pay attention to the functional equivalence of information instead of the direct formal equivalence, and that the relationship between the target language receptor and the target

*Fund: 2017 Higher Education and Teaching Reform Project of Guangdong Province "Cross-border E-commerce Curriculum Innovation Reform and Construction Based on Practical Project Training Mode" (Guangdong Higher Education Official Document [2018]1). text should generally be equivalent to that between the source language receptor and the source text.

Nida points out that translation consists in reproducing the information of source language by using the most appropriate, natural and equivalent language from semantic to stylistic. The equivalence in "dynamic equivalence" includes four aspects: lexical equivalence, syntactic equivalence, textual equivalence, and stylistic equivalence. Among the four aspects, Nida believes that meaning is the first, form is the second, and if the original text and the target text are in different language forms, the translator is required to change the form of the original text to preserve the content and culture of the source language.

\section{CROSS-BORDER E-COMMERCE ENGLISH TRANSLATION}

\section{A. Characteristics of cross-border e-commerce English translation}

The English vocabulary of cross-border ecommerce is much different from the ordinary English vocabulary, and has some characteristics of its own. The followings are the characteristics of cross-border e-commerce English term.

The English vocabulary of cross-border ecommerce is strong in speciality, which mainly uses written official words, so it advocates to use professional words with single meaning instead of using words with flexible meaning or multiple 
meanings. The sentence also avoids using the writing techniques, such as exaggeration and metaphor. Cross-border e-commerce English should pay attention to the use of some professional words in different stages of trade process, such as product release, order processing, paid transaction and after-sales service. For example, "tie-in sale" refers to "搭售", "inquiry" means "询盘", "down payment" means "定金" etc. Furthermore, the second characteristic of cross-border e-commerce English term is high accuracy. For example, the links of description of product and the transaction payment will involve data presentation, and these data is required to be accurate without any errors. Besides, the terms of the trade clause and after-sale commitments must also be rigorous.

The vocabulary of cross-border e-commerce English has certain particularity, including the use of abbreviations and loanwords. On the one hand, with the rapid development of the network platform, the use of abbreviations has become familiar to the majority of consumers, so it would be more frequently used when the merchants in the cross-border e-commerce platform are making advertisements and introduction of the products. For example, the "UPC" refers to "通用产品编号", "SKU" refers to "库存量单位", etc. On the other hand, the vocabulary of cross-border e-commerce English are particular because they come from Latin, French or Greek, for example, "null and void" means "无效". In addition, most of the formal words used in contract text are also derived from Latin, like "ad diem" means "在指定日期", "status quo" means "现状" etc. Part of them are from French, such as "force majeure" refers to "不可抗力".

1) Vocabulary analysis based on the functional equivalence theory: The vocabulary of cross-border e-commerce English mainly includes professional terms, polysemous words and so on. We mainly combine functional equivalence theory to analyze the characteristics of professional terms and polysemous translation in cross-border e-commerce English vocabulary. Nida's theory of functional equivalence mentions what translation stress is the functional equivalence between two languages instead of the rigid equivalence on the surface of words. And functional equivalence includes four aspects mentioned earlier, namely lexical equivalence, syntactic equivalence, textual equivalence and stylistic equivalence. We can analyze the characteristics of the translation of these two kinds of words from these four aspects.

The cross-border e-commerce English is highly professional, and its meaning is specific, which reflects the formal and precise use of words in cross-border e-commerce English and the principle of lexical equivalence in functional equivalence theory, that is, the meaning of a word lies in its usage in the language. While cross-border ecommerce English terminology focuses on the phrase and vocabulary of the description for specific topic. Besides, the equivalent word of English terminology can often be found in Chinese, corresponding to the lexical equivalence principle in functional equivalence theory. For example, the word "custom" means "海关", "custom duty" is "关税" in cross-border e-commerce English, quite different from the meaning of traditional English "custom". The common word "tolerance" is usually translated as "宽容，容忍", but it's corresponding meaning in cross-border e-commerce English is "公差". In addition, when it comes to trade, law and other highly professional aspects, the professional terms of cross-border e-commerce English can find the corresponding meaning in the target language, and its translation has a certain accuracy and simplicity, so as to reflect the objective rigor and professionalism of its words. For example, "counter sample" refers to "对等样品" instead of "相对货样", and "more or less clause" does not refer to "或多或少 条款" but "溢短装条款". From this point of view, the translation of professional terms in cross-border ecommerce English has certain characteristics of professionalism, simplicity and accuracy.

In terms of polysemous words, it mainly refers to words with multiple meanings. In cross-border ecommerce English, consumers have certain differences in social background, religion and so on, and the same vocabulary will contain different meanings in many cases. We can use textual equivalence in functional equivalence theory to analyze the characteristics of polysemous words' translation in cross-border e-commerce English. Textual equivalence mainly involves contextual context, situational context and cultural context. That is to say, polysemous words' translation has to consider the above two contexts, that is, not only to judge semantics on the basis of language context analysis, but also to consider the specific people, things, communication channels, and the relationship and psychological feelings between participants involved in communication, but also to take into account the social and cultural background historical and cultural traditions of language use.

Taking "break" as an example in different contexts, such as "Do not break the law." or "There is nothing to break through", we can draw from the context involved in the two sentences that the meaning of the word in the former sentence focuses on "违约", while in the latter sentence it emphasizes " 突破". The sentence "Cotton and silk blouses made in China enjoy a good market in North Africa" can be translated as "棉质与丝质女祄衫在北非销路很好" or " 
棉质与丝质女祄衫在北非市场很好". We can see directly that the previous translation of the sentence is better. It takes into account the context and background involved in the whole sentence, and its translation is more accurate and professional, which is conducive to target receptor's understanding, while the last sentence is just a literal translation of the original sentence. Therefore, we can conclude that translation of polysemous words in crossborder English has some flexibility.

2) Sentence analysis based on the functional equivalence theory: The sentence patterns in crossborder e-commerce English are mainly composed of fixed sentences, complex sentences and rhetorical sentences. Sentence is an important part of the article, in addition to achieving equivalence in vocabulary, the translation of sentences should also follow the theory of equivalence. Therefore, we can use the four principles of functional equivalence theory to analyze the characteristics of the above sentence patterns' translation.

Fixed sentences are mainly characterized by the use of fixed sentence patterns to make it easier for consumers to identify language in the process of language . For example, the sentence "Configuring the details of the customized products, including the ordering, final designed, is done online." can be translated as "产品定制的细节包括下单、最终设计等环节

可在线完成". We can see that the translation has the same structure as the original text, also the correspondence of Chinese word order not only reflects syntactic equivalence in functional equivalence, but also reflects lexical equivalence. The translation method is more rigorous, making it easier for consumers to understand.

In the aspect of complex sentence, it mainly refers to the sentence composed of multiple clauses or one clause, which is a common sentence pattern in cross-border e-commerce English. Taking the following sentence as an example, "由于拍摄光线影响 以及显示器不同, 图片与实物相比会有色差, 尽请谅解"，here are two translations of this sentence, the first one is "Because every computer displays differently, pictures and objects will be slightly a little color." while the second one is "There will be a color error because of the different screens shown, also some reasons of taking photo. When you receive the items, may be the color is little different as the pictures shown". [7] Combined with syntactic equivalence and textual equivalence, it can be seen that the first translation is obviously a verbatim translation, without considering grammar and subject, which does not accord with the meaning of the original text. In contrast, the second translation has improved in subject and grammar, but it does not merge information of the whole sentence, also the overall logic and the semantics are not strict enough. According to syntactic equivalence and textual equivalence, the translator should reproduce the meaning of the original text to the greatest extent on the basis of his understanding of the original text. Thus, the original sentence can be translated as "Due to the shooting light and different displays, there will be a little difference on the color. Please understand. Thank you.", which is not only preserves the original meaning, but also satisfies the requirement of semantic smoothness. Therefore, it can be concluded that the sentence with standard structure and rigorous content are the characteristics of complex sentence translation.

In the aspect of rhetorical sentence structure, it is also a sentence form in cross-border e-commerce English. This kind of sentence structure often embodies certain lively characteristics by using more ways such as exaggeration, rhyme or personification, corresponding to stylistic equivalence in functional equivalence theory, stylistic equivalence is that different stylistic works have different language features. Achieving stylistic equivalence needs good command of both source and target language. Different language styles represent different culture elements, for example, "Send melan into sleep." its anthropomorphic translation is "让黑色素沉睡". This advertising word not only reflects the creative thinking of the West, but also takes into account the Chinese sentence style, so that both the target receptor and the original speaker can easily understand, so as to achieve the goal of stimulating consumers' desire to buy.

\section{STRATEGIES OF CROSS-BORDER E- COMMERCE ENGLISH TRANSLATION}

The strategies in cross-border e-commerce English translation include word translation, sentence translation and text translation.

In the aspect of word translation, the commonly used strategies mainly include ellipsis, addition and the choice of meaning. As in pronoun ellipsis, taking the sentence "The computers should be sampled to check the quality before they are shipped" as an example, it can be generally translated as "这批电脑在发货前需进行检查，以保证产品 质量". But when using the way of pronoun ellipsis, the translation should be "电脑在发货前应进行检查". This way can not only show the basic information in the original text, but also accord with the concise characteristics of cross-border e-commerce English, which is helpful to improve the effectiveness of the display of the information on the website of commercial companies.

In terms of sentence translation, the strategies in English translation of cross-border e-commerce are mainly represented in two aspects: inverted 
sentence and passive sentence. In the process of translating inverted sentences, it is necessary to adjust the word order well, which is similar to the general translation of English inverted sentences, including adverbial inversion, attributive inversion and so on. But in passive sentence translation, its use in cross-border e-commerce English is more frequent because English emphasizes the form of language use and needs to describe passive meaning through passive voice, compared with Chinese, which is more inclined to active sentence.

Text translation in cross-border e-commerce English is the main problem that the translators are confronted with. In order to make sure that the translators can grasp the whole structure of the original text, they are not only required to have a high level of the ability of understanding and a better logical thinking capability, but also compliance with the standard of writing. Therefore, the translators should follow the principles of coherence and logic in practical translation. As for coherence, connection, omission and substitution are the main methods to enhance sentence coherence. In terms of logic, the thinking mode of consumers in different cultures should be considered, for example, Chinese people pay attention to the order of cause and effect, while British and the American tend to say the results first and then the reasons. Therefore, the logical requirements of the text should be strictly followed in text translation.

\section{A. Lexical equivalence: word translation}

According to functional equivalence theory, in the process of business contract translation, we can use the conversion method to translate it, that is, to convert one part of speech in English contract, or to convert one part of speech in Chinese into another. For example, the sentence "We should be grateful if you would revise the invoice and let us have a correct copy" can be translated as "如贵方能修订发票， 并回寄更改后的文本，我方将不胜感激", For this example, "grateful" belongs to adjectives, but when translated in Chinese, "感激" belongs to verbs.

There are many methods of cross-border ecommerce English vocabulary translation, such as the ellipsis and addition mentioned before. But many English languages have an extended meaning that cannot be realized through literal translation, which will bring trouble to business negotiation.

In order to achieve functional equivalence, first of all, according to the part of speech to choose the meaning of words, as is known to us, many English words have different parts of speech with different meanings. When we translate cross-border ecommerce English, it is necessary to identify the part of speech of the word in the sentence, and then select the appropriate meaning based on part of speech of this word, then the lexical equivalence of the sentence can be achieved.[8] There is an example as followed:

1a. A particular average is an insurance loss that affects specific interests only.

\section{$1 b$. 单独海损是指仅涉及到特殊利益方的损失。}

2a. I admit I do not know why average degree of happiness has not risen in recent decades in the US as incomes rose.

2b. 我承认我的确讲不清为什么美国的平均幸福度在最 近几十年没有随着收入的增加而提高。

As for "average", in the previous sentence it is a noun in which "particular average" means "单独海损" (a partial loss in marine insurance). However, in the next sentence it is an adjective, which means "平均 的" (the usual level or amount for most people or things).

Taking account of context and lexical collocation is also a good method for word translation of cross-border e-commerce English based on functional equivalence theory which can help to reach equivalence in the meaning at lexical level. When we translate cross-border e-commerce English materials, the word's meaning can be influenced by the context and lexical collocation because a word in English often contains more than one meanings. Therefore, it is essential to choose the suitable meaning of the word according to the content or lexical collocation. There is an example as followed:

2a. As well as setting the shape you can set the tolerance for the picking operation.

\section{2b. 除了设定形状之外你还可以设定拣选操作的公差。}

3a. The one thing I learned is tolerance and appreciation of all people.

\section{$3 b$. 我学到的一件事件就是要宽容和感激所有人。}

As for "tolerance", it means "公差" (the amount by which the measurement of a value can vary without causing problems) in the first sentence, and "宽容" (the willingness to accept somebody or something) in the second one.

\section{B. Equivalence in sentence translation: syntactic equivalence}

According to the theory of functional equivalence, "syntactic equivalence" refers to that the information of the original text is equivalent to the target text's information. And there are differences between different languages, there is no corresponding translation for each word. The real semantic equivalence is that the translator 
reproduces the meaning and form of the original text to the greatest extent after understanding the content of the original text, which is free translation. For example, a word with a higher frequency in a business English contract is "subject to", its original translation is "使服从". But in different commercial contract translation, the main purpose of this term is to determine and execute the contract, such as "Subject to the above stipulation ..." should be translated as "以.....为条件", which is more accurate and easy to understand than the original meaning.

Sentence is an important part of the article, the translation of sentences should also follow the theory of equivalence. Firstly, the cultural background in the original text should be reflected. Secondly, the structure of the original text and some words should be changed according to the actual needs, but cannot change the basic meaning of the sentence. Equivalence requires translation to accurately express the meaning of the article or language.

When translating sentences in cross-border ecommerce English, we should first pay attention to translating long sentences, passive sentences and establishing sentence patterns according to the syntactic characteristics of cross-border ecommerce English. For example, the sentence "Also known as build-to-order, customization can be done on a large scale, in which case it is called mass customization." It is known that "customization also known as build-to-order" is the passive sentence, if it is translated literally, the translation will be "定制可叫做按单生产". But this translation method is completely different from the Chinese word order, so based on functional equivalence, it needs to be translated as "定制也称按 单生产". "It is called mass customization" in the sentence should be translated as "亦称大批量制定". [7] Therefore, in the actual translation process, we should focus on distinguishing two problems, including how to translate English passive sentence into Chinese passive sentence, and how to express English passive sentence in Chinese active sentence.

\section{Equivalence in text translation: stylistic equivalence and cultural equivalence}

Cross-border e-commerce English text translation based on functional equivalence theory requires translators to complete functional equivalence between words and sentences first. That is to say, we must first analyze words and sentences based on functional equivalence and then analyze the text based on the deep meaning and style of it. The professionalism of cross-border ecommerce English discourse requires translator to pay attention to the cultural characteristics of the West and its language expression and use the English language structure in translation. Due to the differences between Chinese and Western people in language habits, cultural backgrounds and ways of thinking, even if the equivalence of words and sentences is realized in many cases, the functional equivalence of discourse still cannot be guaranteed. At this time, we can make some adjustments to the whole text structure in order to achieve the equivalence of language function and effect.

Stylistic equivalence means that the translation of cross-border e-commerce English should conform to the style of the original text in order to achieve stylistic equivalence of the source text and target text. The translation style of cross-border ecommerce products is business translation style, which requires the language to be simple and easy to understand, and the expression is accurate. Product introduction should include as much information as possible, but should pay attention to information classification and highlight the key points. As in the following example, "Plus Size M4XL Men Jacket Male Casual Slim Fit Mandarin Collar Solid Jackets New 2017 Men's Fashion Overcoat Brand Clothing", this is a title of men's jacket in cross-border e-commerce website. [10] Although the title presents all the information about the jacket, it does not highlight the core vocabulary and does not meet the requirement of simplicity and clarity in cross-border e-commerce English translation, resulting in consumers visual fatigue. Hence it cannot stimulate the consumers' desire to buy and cannot achieve stylistic functional equivalence.

"Cultural equivalence" means cultural information equivalence between original text and target text. There are cultural differences in different countries, and these cultural differences will more or less cause a deviation in understanding. In order to open up the international market and attract foreign consumers, cross-border e-commerce should narrow these cultural differences as far as possible in the translation of advertising words and product information by showing the characteristics of products intuitively in order to stimulate the consumers' desire to buy. Sprite's ad says, "Obey your thirst" (服从你的渴望). Westerners pursue individualism, with personal value as the center, emphasizing personality and independence, advocating personalized products, and product translation will emphasizes individuals as well.

\section{CONCLUSION}

The paper explores cross-border e-commerce English translation based on functional equivalence theory and proposes some strategies in the cross- 
border e-commerce translation practice. It holds that Nida's "equivalence" should not be mechanically applied, but to achieve the most natural equivalence in cross-border e-commerce translation. The use of equivalence theory helps to improve the standardization of cross-border ecommerce English translation.

\section{References}

[1] Duan Lingshuang. An Analysis of the Language Features and Translation Problems of Business English in Crossborder E-commerce [J]. English Square. 2016(02): 49-50.

[2] Chen Wenjie, Wu Ronglan. The Application of Business English in Cross-border E-commerce [J]. Modern Trade Industry, 2018,39(15): 65-67.

[3] Yuhui Feng, Meiyun Hua. Research on Non-verbal Graphic Symbol Communication of Cross-border Ecommerce [J]. Digital Services and Information Intelligence, 2014, 445.

[4] Zhang Meimei. A Study of Business Contract English Vocabulary Translation from the Perspective of Functional Equivalence Theory [J]. Technological Horizon. 2014(08).

[5] He Jiayuan. Translation Strategy of External Publicity from the Perspective of Functional Equivalence Theory [J]. International Forum of Teaching \& Studies, 2019, 15(1).

[6] Shi Xuedong. Chinese-characterized Terms Translation on the Functional Equivalence Theory [J]. Journal of Language Teaching \& Research, 2014,5(5)

[7] Feng Lin, Xu Hongmin. A functional equivalence study of E-business Web Pages from Chinese to English [J]. Drama House, 2018(30):195-197.

[8] He Fan. The Application of Functional Equivalence Theory in Business English Translation [J]. Trade, 2014(18). 